\title{
Codon 141 polymorphisms of the ovine prion protein gene affect the phenotype of classical scrapie transmitted from goats to sheep
}

Timm Konold ${ }^{1 *}$ (D), Laura J. Phelan, Ben R. Donnachie², Melanie J. Chaplin², Saira Cawthraw ${ }^{3}$ and Lorenzo González ${ }^{4}$

\begin{abstract}
Background: A study to investigate transmission of classical scrapie via goat milk was carried out in sheep: firstly, lambs were challenged orally with goat scrapie brain homogenate to confirm transmission of scrapie from goats to sheep. In the second study phase, milk from scrapie-infected goats was fed to lambs. Lambs were selected according to their prion protein gene (PRNP) genotype, which was either VRQNRQ or ARQ/ARQ, with or without additional polymorphisms at codon $141\left(\mathrm{FF}_{141}, \mathrm{LF}_{141}\right.$ or $\left.\mathrm{LL}_{141}\right)$ of the ovine PRNP. This report describes the clinical, pathological and molecular phenotype of goat scrapie in those sheep that progressed to clinical end-stage.

Results: Ten sheep (six VRQ/NRQ and four $A R Q / A R Q$, of which three $F F_{141}$ and one $L_{141}$ ) challenged with one of two scrapie brain homogenates, and six pairs of sheep (ARQ, of which five $L_{141}$ and seven $L F_{141}$ ) fed milk from six different goats, developed clinical disease, which was characterised by a pruritic (all VRQNRQ and $L L_{141}$ sheep) or a non-pruritic form (all $\mathrm{LF}_{141}$ and $\mathrm{FF}_{141}$ sheep). Immunohistochemical (IHC) examination revealed that the pattern of intra- and extracellular accumulation of disease-associated prion protein in the brain was also dependent on PRNP polymorphisms at codon 141, which was similar in $\mathrm{VRQ}$ and $\mathrm{LL}_{141}$ sheep but different from $\mathrm{LF}_{141}$ and $\mathrm{FF}_{141}$ sheep. The influence of codon 141 was also seen in discriminatory Western blot (WB), with $\mathrm{LF}_{141}$ and $\mathrm{FF}_{141}$ sheep showing a bovine spongiform encephalopathy-like profile (diminished reactivity with P4 antibody) on brain tissue. However, discriminatory WB in lymphoid tissues, and IHC pattern and profile both in lymphoid and brain tissue was consistent with classical scrapie in all sheep.
\end{abstract}

Conclusions: This study provided further evidence that the clinical presentation and the pathological and molecular phenotypes of scrapie in sheep are influenced by PRNP polymorphisms, particularly at codon 141. Differences in the truncation of disease-associated prion protein between $L_{141}$ sheep and those carrying the $F_{141}$ allele may be responsible for these observations.

Keywords: Scrapie, Transmission, Goat, Sheep, Clinical picture, Immunohistochemistry, Western immunoblot, PRNP genotype, Codon 141, Prion protein

\footnotetext{
*Correspondence: Timm.Konold@apha.gsi.gov.uk

${ }^{1}$ Animal Sciences Unit, Animal and Plant Health Agency Weybridge,

Addlestone, UK

Full list of author information is available at the end of the article
} 


\section{Background}

Classical scrapie is a transmissible spongiform encephalopathy (TSE) of sheep and goats that can be transmitted vertically from dam to offspring and horizontally between animals. Horizontal transmission was demonstrated not only between conspecifics but also from sheep to goats under natural conditions [1, 2], whereas natural transmission from goats to sheep has not been reported. One study described the successful transmission of goat scrapie to sheep by intracerebral inoculation of pooled goat brains [3] but this was prior to the development of more sensitive diagnostic methods and before the effect of prion protein gene (PRNP) genotype on disease susceptibility was known.

Three codons are considered important regarding scrapie susceptibility in sheep: codon 136, encoding alanine (A) or valine (V), codon 154, encoding arginine (R) or histidine $(\mathrm{H})$ and codon 171 , encoding glutamine $(\mathrm{Q})$ or arginine (R). In Cheviot sheep, the most susceptible genotype is VV at codon 136, RR at codon 154 and QQ at codon $171\left(\mathrm{VV}_{136} \mathrm{RR}_{154} \mathrm{QQ}_{171}\right)$ whereas $\mathrm{AA}_{136} \mathrm{RR}_{154} \mathrm{RR}_{171}$ sheep are considered highly resistant [4]. There are other PRNP polymorphisms, such as phenylalanine (F) instead of leucine (L) at codon 141, which have been associated with atypical scrapie cases [5], and increased survival times were reported in $\mathrm{AA}_{136}$ Cheviot sheep with an $\mathrm{F}_{141}$ allele, which had been experimentally inoculated with classical scrapie [6]. PRNP polymorphisms also affect classical scrapie susceptibility in goats. For example, lysine (K) instead of glutamine $(\mathrm{Q})$ at codon 222 is associated with increased resistance, and methionine $(\mathrm{M})$ instead of isoleucine (I) at codon 142 is linked to an increased survival time [7].

A more recent study demonstrated transmission of classical scrapie from a goat $\left(\mathrm{II}_{142}\right)$ to two of four $\mathrm{VV}_{136} \mathrm{RR}_{154} \mathrm{QQ}_{171}$ sheep by oral inoculation with placenta [8] but there was very limited information on the disease phenotype.

The study reported here aimed to provide more detailed information about the clinical, pathological and molecular phenotype of caprine classical scrapie in sheep, in particular with respect to PRNP polymorphisms at codon 141 that were detected in these sheep. The disease was produced as part of an experiment to assess the infectivity of goat milk following a pilot study to determine susceptibility of sheep to goat scrapie, the results of which were presented separately [9].

\section{Methods}

\section{Animal studies}

For the pilot study to determine susceptibility of sheep to goat scrapie, brain homogenates were prepared from two naturally infected Anglo-Nubian goats [10] according to established methods [11]: G1460 with $\mathrm{II}_{142}$ and G1451 with $\mathrm{IM}_{142}$ PRNP genotypes. All goats were from a herd that was culled to eradicate scrapie in accordance with Regulation (EC) No 999/2001 and its amendments laying down rules for the prevention, control and eradication of certain transmissible spongiform encephalopathies. More details on these goats are provided elsewhere [12, 13].

Brain recipients were 10 Cheviot lambs with PRNP genotypes $\mathrm{VV}_{136} \mathrm{RR}_{154} \mathrm{QQ}_{171}(n=6$, subsequently called $\mathrm{VV})$ and $\mathrm{AA}_{136} \mathrm{RR}_{154} \mathrm{QQ}_{171}(n=4$, subsequently called AA) born from six ewes from our research flock that was established in England to provide classical scrapiefree sheep for research purposes [14]. PRNP genotyping was performed as described previously [15] and included polymorphisms at codon 141, which have shown to influence disease in experimentally infected AA sheep [6] ( $\mathrm{L}_{141}$ or $\mathrm{F}_{141}$ subsequently called $\mathrm{LL}_{141}, \mathrm{LF}_{141}$ or $\mathrm{FF}_{141}$ ). When the study started, recipient sheep were purely selected on the basis of their polymorphisms at codon 136 (VV or AA) to determine the most suitable genotype for a goat scrapie transmission study to sheep. As dam and sire of recipient AA sheep were not both homozygous $\mathrm{LL}_{141}$ or $\mathrm{FF}_{141}$, recipients were $\mathrm{LL}_{141}, \mathrm{LF}_{141}$ or $\mathrm{FF}_{141}$.

The lambs were orally challenged within $24 \mathrm{~h}$ of birth with $5 \mathrm{~g}$ (as 10\% $\mathrm{w} / \mathrm{v}$ solution in physiological saline) of one of the two goat brain homogenates. Lambs were raised by their dams until weaning at approximately 10 weeks of age in three pens, two of which contained lambs challenged with either G1460 or G1451 brain and one housed a mixture of lambs challenged with G1460 or G1451 brain (Table 1). Lambs from the different pens were mixed from 35 months of age when the number of animals started to decline.

For the milk transmission study, recipients were six pairs of AA lambs with either $\mathrm{LL}_{141}$ or $\mathrm{LF}_{141}$ PRNP polymorphisms from the same classical scrapie-free flock because the pilot study implied that AA sheep were more suitable as recipients than VV sheep. As mentioned above, uniform genotypes at codon 141 could not be pre-selected in the recipient sheep although this time dams and sire were chosen to produce either $L_{141}$ or $\mathrm{LF}_{141}$ lambs because infection in the pilot study was first demonstrated in AA sheep with an $\mathrm{L}_{141}$ allele [9]. The lambs were fed milk from six different scrapie-infected goats (volume 38-87 l per lamb), which were all from the same herd and included the two goats that also provided brains for the pilot study. Once all the goat milk was consumed, lambs were fed milk replacer (Lamlac, Volac International Ltd., Orwell, UK). Pairs of milk recipients were kept separate until scrapie infection was confirmed by rectal biopsy (see below), at which time they were mixed. All sheep were fed straw and concentrates after weaning at approximately 10 weeks of age.

A graphic representation of the study design is provided as Additional file 1: study design. 
Table 1 Animal details

\begin{tabular}{|c|c|c|c|c|c|}
\hline Animal ID & $\operatorname{Sex}^{a}$ & PRNP codon 136 and 141 & Source of infection & Donor & Survival time $[\mathrm{d}]$ \\
\hline 1418 & $\mathrm{M} / \mathrm{N}$ & W LL & Brain & G1451 & 1167 \\
\hline 1419 & $M / N$ & W LL & Brain & G1451 & 1220 \\
\hline 1451 & $M / N$ & W LL & Brain & G1451 & 1452 \\
\hline 1424 & $M / N$ & W LL & Brain & G1460 & 1154 \\
\hline 1425 & $\mathrm{M} / \mathrm{N}$ & W LL & Brain & G1460 & 1073 \\
\hline 1452 & $M / N$ & W LL & Brain & G1460 & 1158 \\
\hline 1473 & $\mathrm{M} / \mathrm{N}$ & AA LL & Brain & G1460 & 1060 \\
\hline 1319 & $\mathrm{~F}$ & AA LL & Milk (82 I) & G1415 & 1122 \\
\hline 1294 & $\mathrm{~F}$ & AA LL & Milk (76 I) & G1427 & 1243 \\
\hline 1293 & $\mathrm{M} / \mathrm{N}$ & AA LL & Milk (76 I) & G1427 & 1284 \\
\hline 1286 & F & AA LL & Milk (87 I) & G1383 & 1285 \\
\hline 1329 & $\mathrm{M} / \mathrm{N}$ & AA LL & Milk (63 I) & G1451 & 1298 \\
\hline 1287 & F & AA LF & Milk (87 I) & G1383 & 1325 \\
\hline 1321 & $\mathrm{~F}$ & AA LF & Milk (38 I) & G1460 & 1333 \\
\hline 1324 & F & AA LF & Milk (57 I) & G1143 & 1460 \\
\hline 1302 & $M / N$ & AA LF & Milk (67 I) & G1451 & 1466 \\
\hline 1323 & F & AA LF & Milk (57 I) & G1143 & 1486 \\
\hline 1322 & $M / N$ & AA LF & Milk (38 I) & G1460 & 1493 \\
\hline 1320 & F & AA LF & Milk (82 I) & G1415 & 1552 \\
\hline 1472 & $M / N$ & AA FF & Brain & G1451 & 1429 \\
\hline 1476 & F & AA FF & Brain & G1451 & 1464 \\
\hline 1471 & $\mathrm{M} / \mathrm{N}$ & AA FF & Brain & G1460 & 2030 \\
\hline
\end{tabular}

${ }^{\mathrm{a}} \mathrm{F}$ female, $\mathrm{M} / \mathrm{N}$ male neutered

\section{Monitoring scrapie infection status}

Scrapie infection status was determined by the immunohistochemical examination of biopsies of recto-anal mucosa-associated lymphoid tissue (RAMALT) [16] from 6 months (pilot study) and 9 months (milk transmission study) of age; rectal biopsies were repeated only in sheep with previously negative results.

Sheep were monitored twice daily by farm staff and were systematically examined for neurological signs first at 20 months of age, then at 31 months and then usually monthly or more frequently depending on clinical status, using a short examination protocol for detection of scrapie [17]. A full neurological examination [11] was carried out prior to culling, and an electrocardiogram was recorded as described previously [18] in those sheep where cardiac arrhythmia was suspected during the physical examination. To document progressive pruritic behaviour, a scratch test score was calculated retrospectively. This was the number of consecutive positive responses (unequivocal stereotypical behaviour [19] until culling divided by the total number of clinical assessments ranging from 0 (no response prior to cull) to 1 (response at each assessment until cull). Inconclusive responses [19] counted towards positive reactions if they occurred prior to a positive response because it was interpreted as early sign of pruritus consistent with the progressive nature of scrapie. Thus, an inconclusive response followed by no scratch response on the subsequent examination or a positive scratch test that disappeared prior to culling did not count as consecutive positive response until culling because clinical signs were less likely to be associated with a progressive disease if they disappeared.

Assessments were made blind without knowledge of the genotype or inoculum although the scrapie status was known once animals were mixed. Sheep were euthanased with intravenous injection of secobarbital and cinchocaine (Somulose, Dechra, Shrewsbury, UK) at clinical end-point, which was reached when animals displayed progressive abnormalities in sensation (positive scratch test with or without alopecia, absent menace response) and movement (ataxia, limb weakness, tremor).

\section{Post-mortem investigation}

The brain and a range of lymphoid tissues were taken and processed for immunohistochemistry (IHC) and Western immunoblot (WB) examination. 
For IHC, tissue from the central nervous system (CNS) and lymphoid tissue were formalin-fixed, wax-embedded and examined with six different antibodies, which bind to different amino acid (aa) residues of ovine PrP: BG4 (aa 46-54; the Roslin Institute, Edinburgh, UK), 12B2 (aa 93-99, same as P4; Wageningen University \& Research, Lelystad, Netherlands), 521.7 (aa 100102; courtesy of Jan Langeveld, Wageningen Bioveterinary Research, Lelystad, Netherlands), 9A2 (aa 102104; Wageningen University \& Research), BH1 (aa 143-154; the Roslin Institute, Edinburgh, UK) and R145 (aa 222-226, APHA Weybridge, Addlestone, UK) and are used to distinguish classical scrapie from bovine spongiform encephalopathy (BSE) and CH1641-like strains [20, 21]. The discriminatory IHC was applied to nine AA sheep, three each with the different polymorphisms at codon 141, which had similar scrapie-associated prion protein $\left(\operatorname{PrP}^{\mathrm{sc}}\right)$ profiles and total amount of $\operatorname{PrP}^{\mathrm{sc}}$ (see below). A naturally infected classical scrapie sheep, a sheep orally challenged with BSE brain homogenate and a sheep intracerebrally inoculated with $\mathrm{CH} 1641$ brain homogenate were used as controls; all three controls were AALL $\mathrm{A}_{141}$. The robustness of the discriminatory IHC has been previously demonstrated [20].

Lesion profiling was carried out as described previously [6]: tissue sections of the brain at seven levels were immunolabelled with antibody R145 for simplified scoring of $\mathrm{PrP}^{\mathrm{sc}}$ on a scale from 0 (none) to 3 (striking) in steps of 0.5 and including 0.2 for trace immunolabelling. Five different $\operatorname{PrP}^{\mathrm{sc}}$ patterns were distinguished: i) intraneuronal, ii) intraglial (intramicroglial and intrastrocytic types combined), iii) extracellular glia-associated (subpial, subependymal, perivascular, stellate and perivacuolar types combined), iv) grey matter neuropilassociated (diffuse particulate, coalescing, perineuronal and linear types combined), and v) other types (ependymal, vascular plaque and non-vascular plaque types combined). The average value for each $\operatorname{PrP}^{\mathrm{sc}}$ pattern from the seven areas examined was used to create an individual $\operatorname{PrP}^{\mathrm{sc}}$ profile and, for grouping by genotype, the profiles constituted the mean of the individual sheep profiles within each genotype group.

WB examination for detection of the proteinaseresistant form of $\mathrm{PrP}^{\mathrm{sc}}\left(\mathrm{PrP}^{\mathrm{res}}\right)$ was carried out on samples of the caudal medulla and medial retropharyngeal lymph node using antibodies Sha31 (aa 156-163) and P4 according to the BioRad TeSeE universal WB protocol (BioRad Laboratories, Hemel Hempstead, UK). Parallel testing with the two specific monoclonal antibodies aids in the discrimination between classical BSE and scrapie where Sha31 detects $\operatorname{PrP}^{\text {res }}$ in both cattle and sheep, whereas $\mathrm{P} 4$ is more selective for scrapie $\mathrm{PrP}^{\mathrm{res}}$ [22]. Additional antibodies used were 12B2,
SAF32 (aa 86-91; SPI-Bio, Bertin Pharma, Montigny le Bretonneux, France) and 9A2. Sigma biotinylated molecular mass markers as well as a known UK classical scrapie (ovine VRQ/VRQ and caprine $\mathrm{II}_{142}$ ) brain sample, known UK bovine BSE brain sample and known ovine VRQ/VRQ non-neural mesenteric lymph node sample (for WB on lymphoid tissue) were included as positive controls for profile comparisons. All control samples were homogenates from a single naturally infected animal. All samples were tested once.

From each sample, $0.35 \mathrm{~g}$ tissue was ribolysed, purified, treated with proteinase $\mathrm{K}$ (following treatment with DNase for all medial retropharyngeal lymph node samples) and $\mathrm{PrP}^{\mathrm{res}}$ concentrated according to the kit instructions and with the reagents supplied. As four samples produced weak profiles upon initial examination of caudal medulla tissue, these samples were processed in duplicate and the pellets combined (double pellets) for subsequent runs. Samples were heated for $4 \mathrm{~min}$ at $100{ }^{\circ} \mathrm{C}$ prior to loading on gels. A sample of $15 \mu \mathrm{l}$ each was loaded in duplicate lanes onto pre-cast $12 \%$ bis-tris gels (Criterion, Bio-Rad) and electrophoresed for $50 \mathrm{~min}$ at $200 \mathrm{~V}$. The proteins were then transferred onto PVDF membranes (115 V for $60 \mathrm{~min}$ ) and blocked (Bio-Rad blocking solution for Sha31 and milk powder solution for other antibodies) for $30 \mathrm{~min}$ at room temperature. They were probed with the kit primary antibody (Sha31) for $30 \mathrm{~min}$ at room temperature and additional antibodies (P4, 12B2, SAF32, 9A2) for $1 \mathrm{~h}$ at room temperature.

The membranes were washed, incubated for $20 \mathrm{~min}$ in Bio-Rad secondary antibody (Sha31) or goat anti-mouse conjugate (P4, 12B2, SAF32, 9A2) at room temperature, washed again and the membranes were incubated with ECL substrate (Amersham) for $1 \mathrm{~min}$. The signal was detected with the Fluor-S Multilmager (Bio-Rad).

The total amount of $\operatorname{PrP}^{\text {res }}$ signal emitted from the diglycosylated, monoglycosylated and unglycosylated protein bands was calculated by means of the volume analysis tool in the Quantity One software (Bio-Rad) for antibodies Sha31 and P4. The global background was subtracted and the ratio for the ovine scrapie control sample set at 1 ; the ratio for the test samples was then calculated relative to the ovine scrapie control sample. The cut off was set at 2.0 and any sample with a ratio below this was considered to be classical scrapie-like and any ratio above this was considered classical BSE-like.

\section{Results}

Animal data, such as PRNP genotype, sex and survival time, of the 22 sheep that developed a TSE (ten challenged with brain, 12 challenged with milk) are provided in Table 1. The influence of PRNP genotype on survival time has already been discussed in the previous publication [9] and will not be mentioned in this manuscript. 


\section{Clinical signs}

Signs of pruritus, characterised by a stereotypical response to scratching of the back (positive scratch test) and/ or alopecia with or without skin lesions suggestive of excessive rubbing, scratching or nibbling were displayed by all 12 sheep that were either VV or $L_{141}$ (see Additional file 2 for an example of the pruritic form). Of the four sheep with alopecia (one VV and three $L_{141}$ sheep), one $L_{141}$ sheep did not display a clear stereotypical response when scratched although the scratch response had been positive at the examination three days earlier. Scratch test scores ranged from 0.21 to 1.0 (median: 0.39) in VV sheep and 0 to 0.79 (median $0.5)$ in $L_{141}$ sheep. None of the $L_{141}$ or $F_{141}$ sheep displayed signs of pruritus and the scratch test score was 0 for all sheep with these polymorphisms. By contrast, the most frequent sign observed in $\mathrm{LF}_{141}$ or $\mathrm{FF}_{141}$ sheep was limb weakness (all three $F_{141}$ and six of seven $\mathrm{LF}_{141}$ ) in combination with ataxia (two of three $\mathrm{FF}_{141}$ and all $L_{141}$ ) whereas limb weakness was observed in only one $\mathrm{LL}_{141}$ sheep even though most of them (all $\mathrm{LL}_{141}$ and four of six VV sheep) were ataxic (see Additional file 3 for an example of the non-pruritic form). A head tremor was present in all six VV sheep but rare in AA sheep; other movement disorders were lip twitches (one $\mathrm{FF}_{141}$ sheep, see Additional file 3 showing this sheep with twitching lips) and spontaneous myoclonus (one $\mathrm{LL}_{141}$ sheep). Bruxism was audible in five of the six $\mathrm{LL}_{141}$ sheep and three of the six VV sheep but only in one $\mathrm{FF}_{141}$ sheep. Infrequent signs were cardiac arrhythmia (two $\mathrm{LL}_{141}$, three $\mathrm{LF}_{141}$, one $\mathrm{FF}_{141}$ sheep; see Fig. 1 for an example), lack of menace response (one VV, $\mathrm{LF}_{141}$ and $\mathrm{FF}_{141}$ sheep), cataplexy-like collapse (one $\mathrm{FF}_{141}$, one $\mathrm{LL}_{141}$ sheep), inappetence (one $\mathrm{LL}_{141}$ sheep), disequilibrium when blindfolded (two VV sheep and one $\mathrm{LL}_{141}$ sheep) and othaematoma (one VV sheep). Table 2 lists the percentage of animals per genotype group that displayed selected clinical signs. Full details of the clinical signs are given in Additional file 4: clinical and pathological data.

\section{Immunohistochemistry}

Fig. 2 shows the total magnitude of $\operatorname{PrP}^{\mathrm{sc}}$ immunolabelling in the brain of each sheep, which reflects the sum of all average scores for the different $\operatorname{PrP}^{\mathrm{sc}}$ patterns. Whilst there was little variation between sheep with an $\mathrm{LF}_{141}$ (mean: 6.20, standard deviation [SD]: 0.69) or $\mathrm{FF}_{141}$ (mean: 5.41, SD: 0.71) PRNP genotype, more variation was seen in VV (mean: 5.55, SD: 2.05) and $\mathrm{LL}_{141}$ sheep (mean: 5.40, SD: 2.08) where the total brain $\operatorname{PrP}^{\mathrm{sc}}$ score in one sheep could be more than double the score in another sheep irrespective of whether they were challenged with brain or milk from the same donors (see 1452 compared with 1424 and 1294 compared with 1293 in Fig. 2).

The mean $\operatorname{PrP}^{\mathrm{sc}}$ profiles of goat brain and milk recipients, separated by PRNP genotype, are shown in Fig. 3. The profiles were similar in $\mathrm{VV}$ and $\mathrm{LL}_{141}$ sheep but differed from the profiles seen in $\mathrm{LF}_{141}$ and $\mathrm{FF}_{141}$ sheep. When the $\operatorname{PrP}^{\mathrm{sc}}$ profiles from individual sheep were compared within the PRNP genotype group (Fig. 4), differences were apparent between $L_{141}$ sheep fed milk from different donors but not between $L_{141}$ sheep, which all displayed similar profiles. Also, challenge with brain from the same donor resulted in profile differences in VV sheep but not in $\mathrm{FF}_{141}$ sheep.

Discriminatory IHC using six different antibodies revealed that antibody detection in the different compartments in CNS tissue of AA sheep was dependent on polymorphisms at codon 141 of the ovine PRNP (see Fig. 5, which shows the immunolabelling pattern in different compartments using six antibodies with different affinity to ovine $\left.\mathrm{PrP}^{\mathrm{sc}}\right)$. In lymphoid tissue, all antibodies

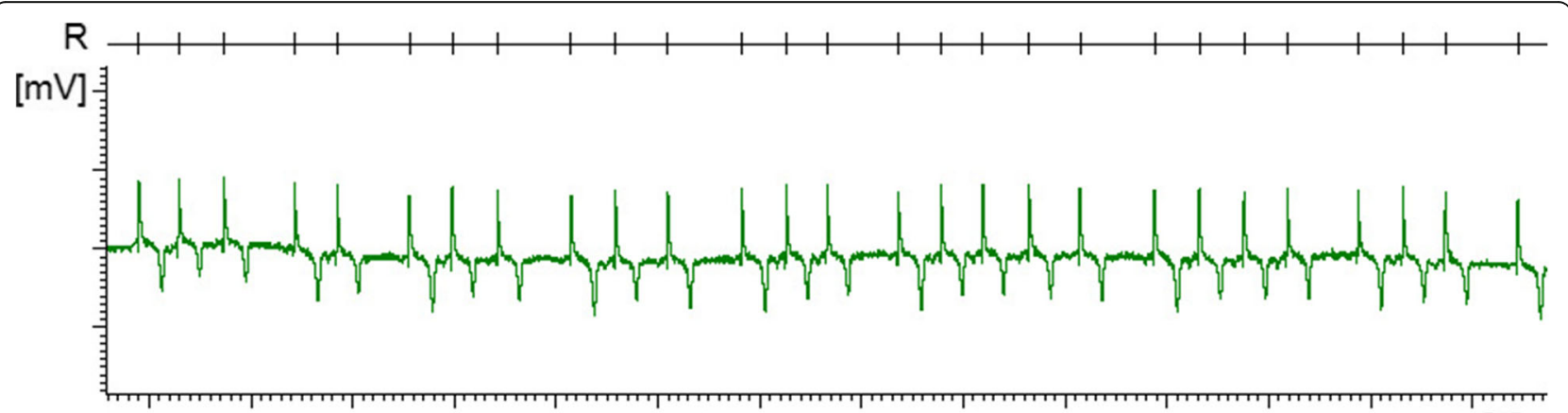

Fig. 1 Electrocardiogram recorded from $L_{141}$ milk recipient 1329 with cardiac arrhythmia. Extract of an electrocardiogram recorded over 5 min prior to cull whilst the animal was restrained in its pen with other sheep; overall heart rate 112 beats per minute. $R=R$ peak intervals; major unit on $x$ axis is second, major unit on y axis is $0.1 \mathrm{mV}$. Note the irregular rhythm of the R peak intervals, which do not appear to follow a particular pattern 
Table 2 Percentage of sheep with selected clinical signs grouped by genotype

\begin{tabular}{|c|c|c|c|c|c|c|c|c|}
\hline PRNP genotype codon 136 and 141 & $N$ & Positive scratch test & Alopecia & Bruxism & Tremor & Ataxia & Limb weakness & Absent menace response \\
\hline$\overline{W L L}$ & 6 & $100 \%$ & $17 \%$ & $50 \%$ & $100 \%$ & $67 \%$ & $0 \%$ & $17 \%$ \\
\hline AA LL & 6 & $83 \%$ & $50 \%$ & $83 \%$ & $33 \%$ & $100 \%$ & $17 \%$ & $0 \%$ \\
\hline AA LF & 7 & $0 \%$ & $0 \%$ & $0 \%$ & $29 \%$ & $100 \%$ & $86 \%$ & $14 \%$ \\
\hline AA FF & 3 & $0 \%$ & $0 \%$ & $33 \%$ & $33 \%$ & $67 \%$ & $100 \%$ & $33 \%$ \\
\hline
\end{tabular}

detected the same levels of $\operatorname{PrP}^{\mathrm{sc}}$ in macrophages, which was consistent with classical scrapie.

Individual scores are shown in Additional file 4: clinical and pathological data.

\section{Molecular profiles}

Molecular profiles obtained by WB testing of caudal medulla with antibodies Sha31 and P4 are shown in Fig. 6. Differences were seen in relation to the reactivity with the N-terminal antibody $\mathrm{P} 4$, which was dependent on PRNP polymorphisms at codon 141: $\operatorname{PrP}^{\text {res }}$ was detected with this antibody in $\mathrm{VV}$ and $\mathrm{LL}_{141}$ sheep, similar to the classical scrapie ovine and caprine control samples, whereas reactivity was reduced in $L_{141}$ sheep and greatly reduced or absent in $\mathrm{FF}_{141}$ sheep, similar to the classical BSE control sample. Similar observations were made with two further N-terminal antibodies, 12B2 and
SAF32. The Sha31/P4 antibody ratios were less than 2 for $\mathrm{VV}$ and $\mathrm{LL}_{141}$ sheep as seen with the classical scrapie control samples, but above 2 in $\mathrm{LF}_{141}$ and $\mathrm{FF}_{141}$ sheep. In fact, the ratio was above 5 in 4 of $7 \mathrm{LF}_{141}$ sheep and in all $\mathrm{FF}_{141}$ sheep (Fig. 7). By contrast, WB reactivities to Sha31 and P4 antibodies on medial retropharyngeal lymph node samples were similar for all sheep, regardless of the 141 polymorphism, and similar to the classical scrapie control samples.

\section{Discussion}

Although this study was originally carried out to investigate the transmission of scrapie via goat milk using sheep as recipients it has provided valuable information about the influence of the PRNP genotype, particularly at codon 141, on the clinical, pathological and molecular phenotype of goat scrapie in sheep. It has been demonstrated

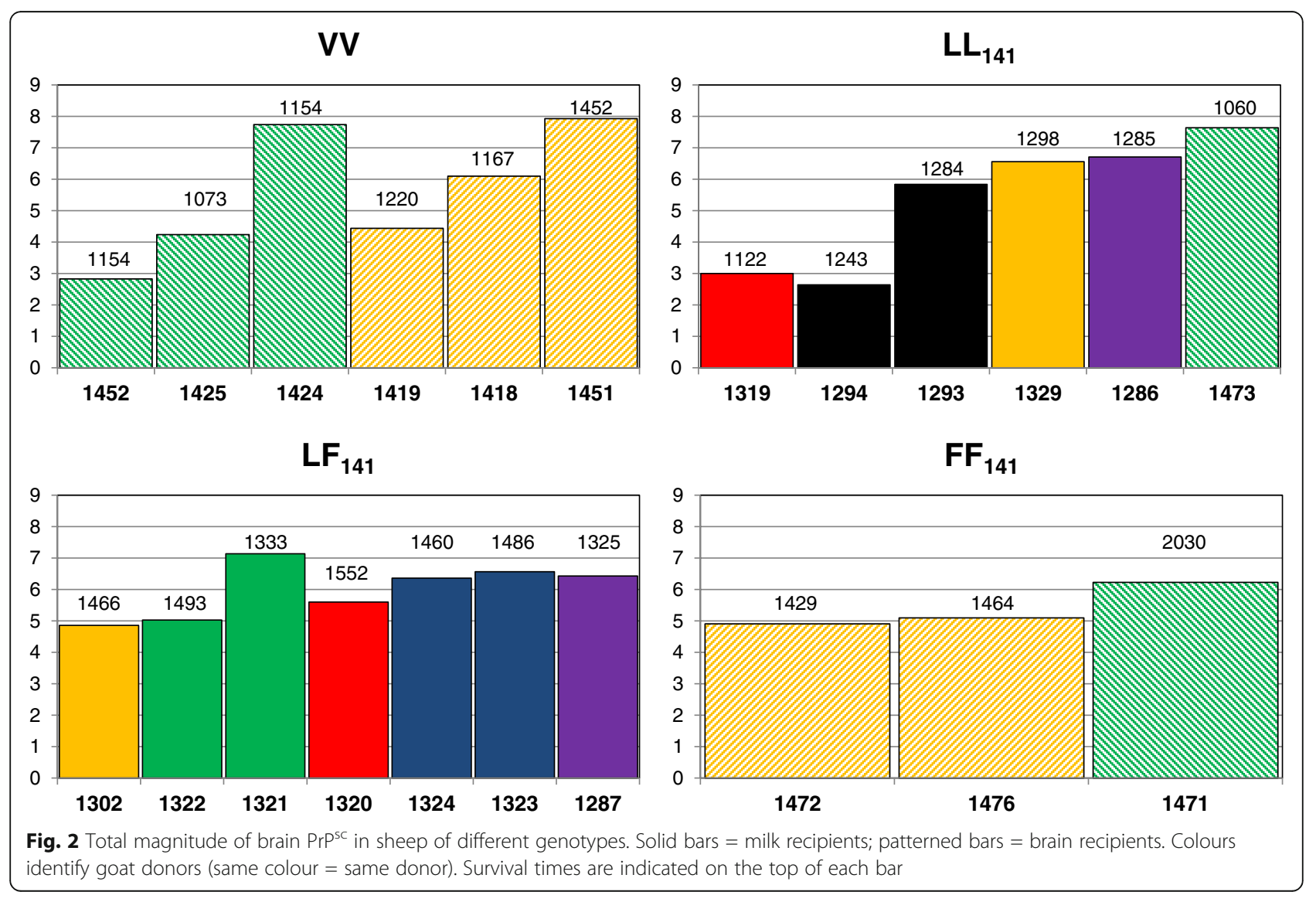



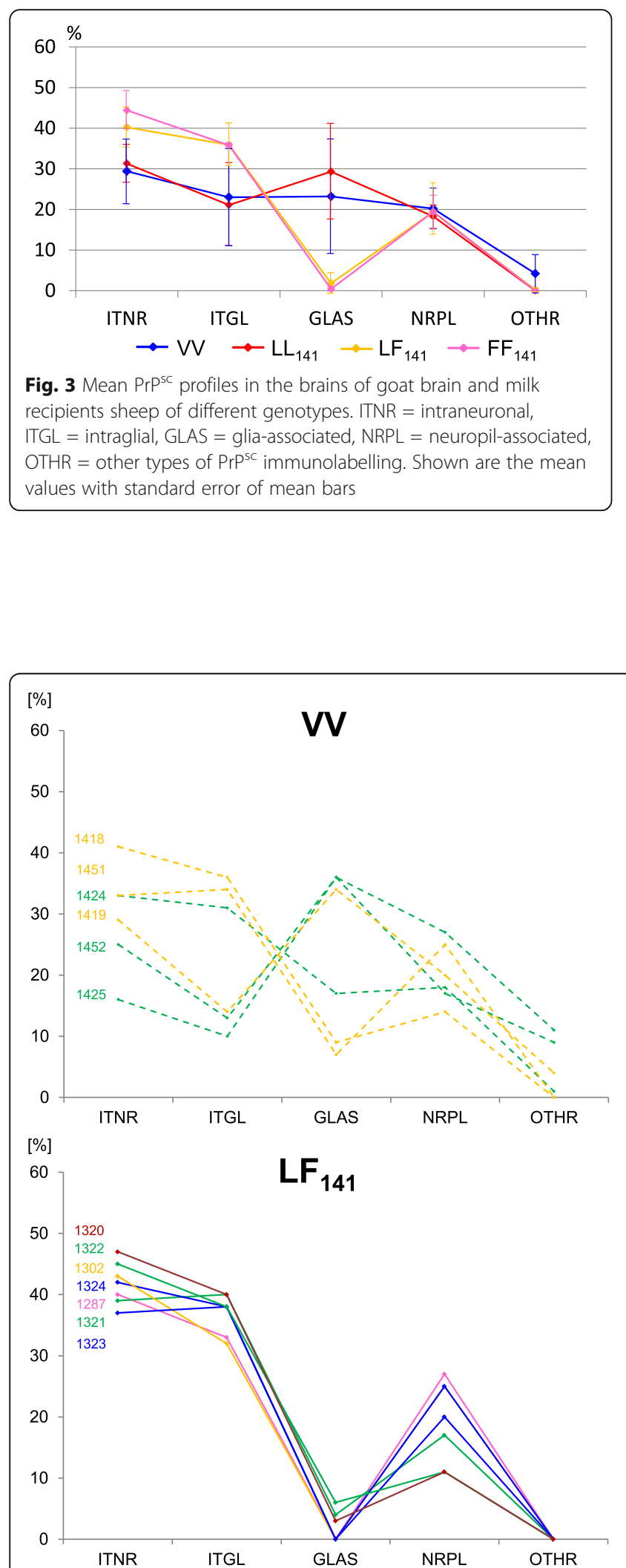

previously that polymorphisms at codon 141 may affect survival time and disease phenotype in sheep on crossPRNP genotype inoculations with pooled sheep brain homogenate [6].

Clinically affected sheep presented with a range of clinical signs, which have been reported previously in sheep with scrapie and indicated that caprine scrapie transmitted to sheep produced a clinical disease associated with scrapie in sheep. This included less common signs such as cardiac arrhythmia, cataplexy-like collapse and othaematoma, possibly as a result of excessive pruritus, which have nevertheless been reported in natural scrapie in sheep [18, 23-26]. Other involuntary movements, such as myoclonus (brief shock-like jerks due to sudden involuntary contraction of one or more muscles [27]) have been reported in some cases of scrapie [28, 29] but are usually more frequent in BSE in cattle or Creutzfeldt-Jakob disease in humans and often in response to an external stimulus (startle myoclonus) [30-32].
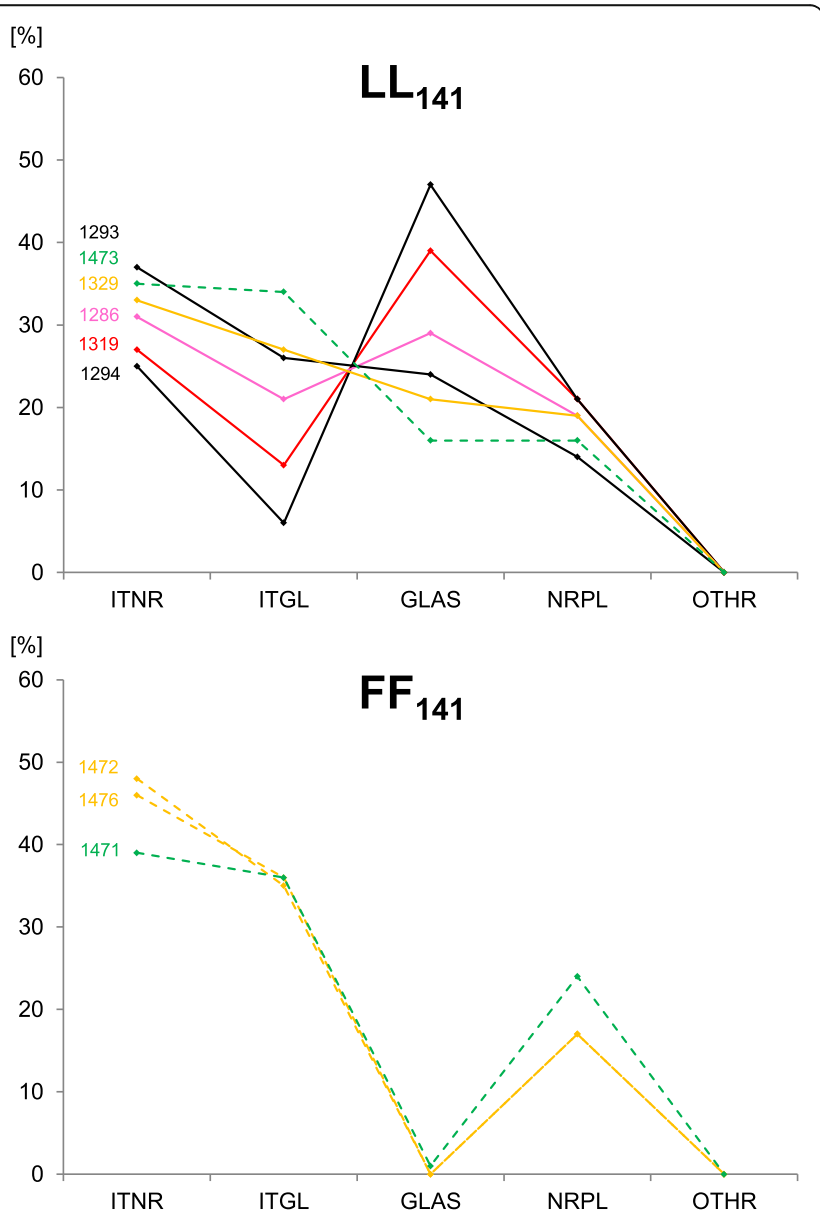

Fig. 4 Brain $\mathrm{PrP}^{\mathrm{sC}}$ profiles of individual sheep. Solid lines = milk recipients; dashed lines: brain recipients. Colours identify goat donors (same colour = same donor). ITNR = intraneuronal, ITGL = intraglial, GLAS = glia-associated, NRPL = neuropil-associated, OTHR = other types of PrPsc immunolabelling 

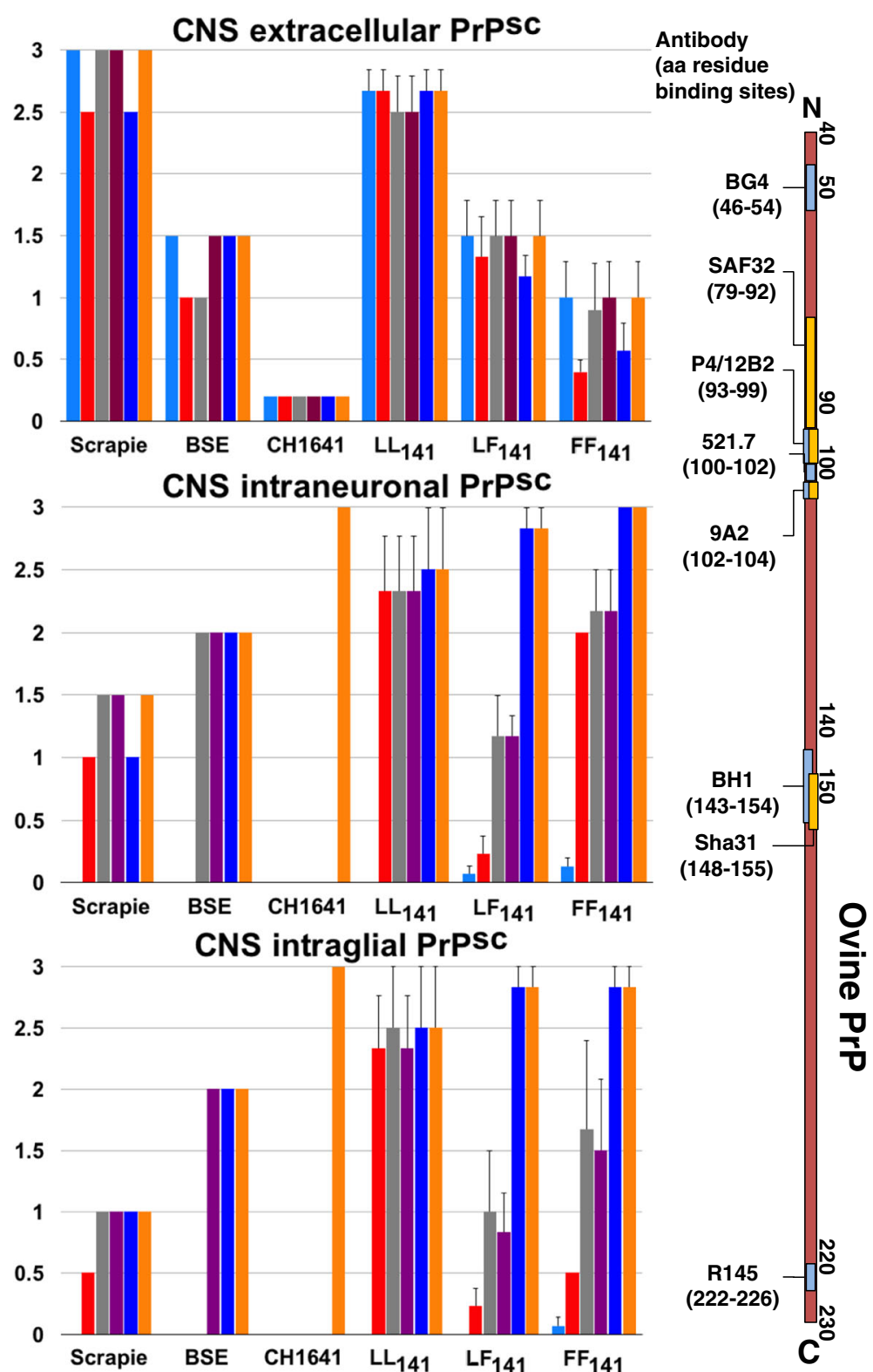

Fig. 5 Differences in $\mathrm{PrP}^{\mathrm{sc}}$ localisation depending on codon 141 polymorphisms observed by discriminatory immunohistochemistry on brain tissue using six different antibodies. Classical scrapie, classical ovine BSE and the CH1641 strain (single animals) are shown for comparison. Shown are the mean values with standard error of mean bars. The diagram on the right represents the ovine prion protein and the binding sites of the antibodies used in this study

Clinical disease in sheep may vary according to breed, region and country, presenting either as pruritic or nonpruritic form [33]. The results presented here clearly demonstrate that the clinical phenotype is affected by PRNP genotype, notably polymorphisms at codon 141, of sheep of the same breed. All $L_{141}$ sheep (regardless of donor goat and PRNP genotype at codon 136, VV or AA) exhibited the pruritic form, which is also the predominant form in sheep infected with the BSE agent and characterised by a positive scratch test (lip licking or head movements when the back is scratched), excessive rubbing and scratching resulting in wool loss [19]. By contrast, $\mathrm{LF}_{141}$ and $\mathrm{FF}_{141}$ sheep presented with the nervous form, characterised by ataxia and limb weakness without any signs of pruritus, regardless of donor goat, which is clinically unlike experimental BSE in sheep. These results provided further evidence that the clinical presentation is dependent on the PRNP genotype as suggested by studies in naturally infected sheep where strain as confounding factor could not be excluded [29, 34]. 


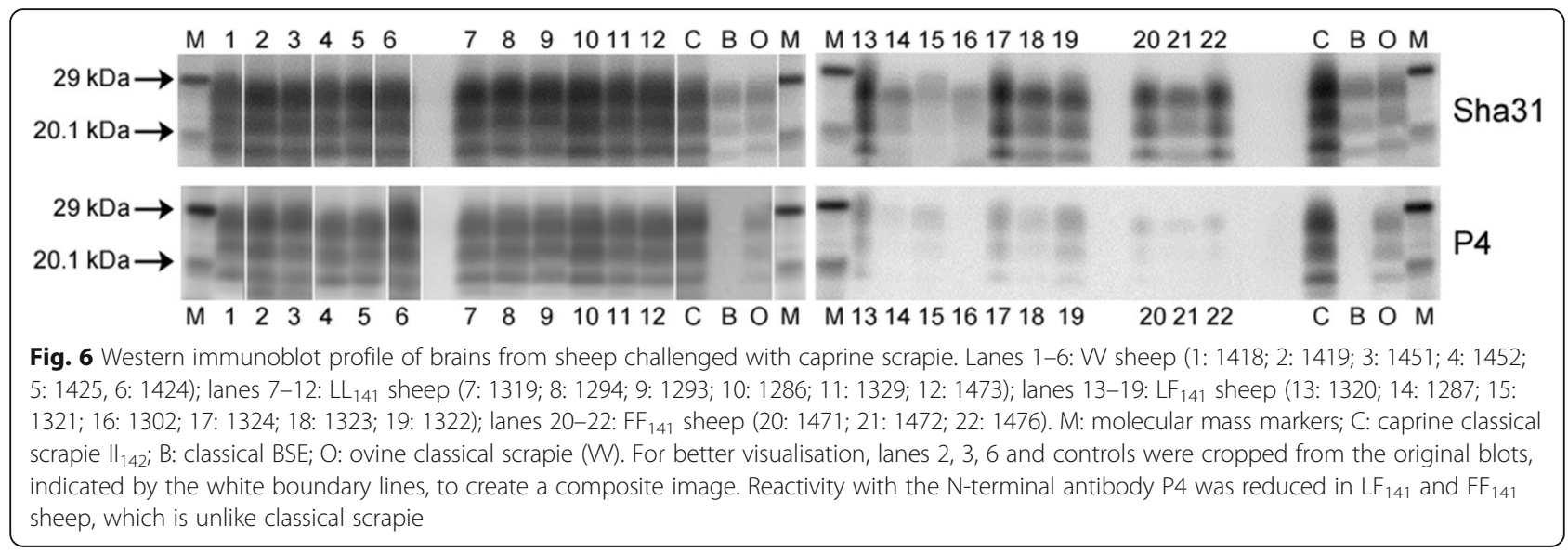

The results also provided further evidence that the pathological phenotype was influenced by the PRNP genotype at codon 141. $\operatorname{PrP}^{\mathrm{sc}}$ profiling by genotype revealed that the profiles did not differ between $\mathrm{LF}_{141}$ and $\mathrm{FF}_{141}$ sheep, which was characterised by the predominance of intraneuronal and intraglial $\mathrm{PrP}^{\mathrm{sc}}$ and an absence of extracellular glia-associated $\operatorname{Pr} \mathrm{P}^{\mathrm{sc}}$, which was in contrast to $L_{141}$ sheep (either $V V$ or $A A$ ) where glia-associated $\operatorname{PrP}^{\mathrm{sc}}$ was more prominent (see Fig. 3). These findings were consistent with results from studies in naturally infected sheep or sheep with scrapie induced by experimental cross-genotype transmission, which suggested that $\operatorname{PrP}^{\mathrm{sc}}$ profiles were influenced by PRNP genotypes although other factors, such as source of infection and survival time could also be contributory $[6,35]$.

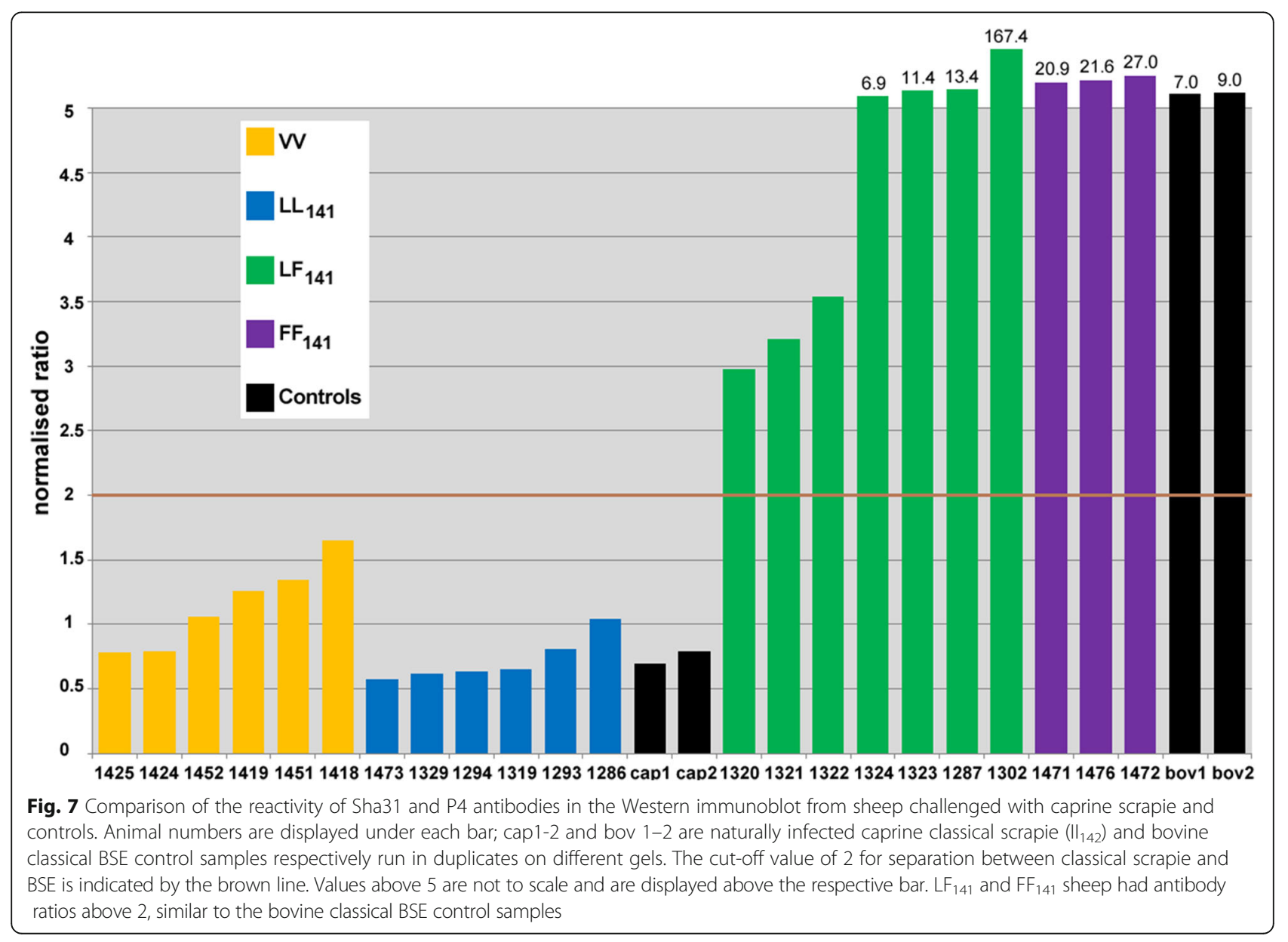


There is evidence from studies in experimentally and naturally infected sheep with scrapie that there is poor association between the severity of clinical signs and the level of $\operatorname{PrP}^{\text {res }}$ [36] or $\operatorname{PrP}^{\mathrm{sc}}$ in the brain [37-39]. This was confirmed in the present study, using an established $\mathrm{PrP}^{\mathrm{Sc}}$ profiling method and detailed and regular clinical examinations for signs of scrapie. If the large variation in the total magnitude of $\operatorname{PrP}^{\mathrm{sc}}$ immunolabelling in some $\mathrm{VV}$ and $\mathrm{LL}_{141}$ sheep was due to the difference in survival times and the severity of clinical signs despite having been infected with identical volumes of milk or doses of brain from the same donor, sheep with lower total $\mathrm{PrP}^{\mathrm{sc}}$ scores should have shorter survival times with less severe clinical signs. However, this was not consistently observed. For example, the survival time was not necessarily longer in sheep with a higher $\operatorname{PrP}^{\mathrm{sc}}$ score $(1452$ was culled later than 1424 even though the total $\operatorname{PrP}^{\mathrm{sc}}$ was two times higher in 1424). Studies on the clinical progression in naturally affected sheep with scrapie suggested that head tremor, ataxia, teeth grinding, loss of body condition and loss of a menace response occurred more frequently with disease progression $[29,40]$. There was some indication that sheep with higher $\operatorname{PrP}^{\mathrm{sc}}$ scores, which had been challenged with milk or brain from the same donor, presented with more severe clinical signs: both brain-challenged VV sheep with a lower $\operatorname{PrP}^{\mathrm{sc}}$ score (1452 and 1425) were not ataxic and had a menace response unlike the other VV sheep (1424), which was ataxic, lost the menace response and had a considerably higher $\operatorname{PrP}^{\mathrm{sc}}$ score. Similarly, the severity of ataxia was considered less in an $\mathrm{LL}_{141}$ sheep with low $\operatorname{PrP}^{\mathrm{sc}}$ score (1294) compared to one with a high $\operatorname{PrP}^{\mathrm{sc}}$ score (1293), which also lost its appetite. However, two other VV sheep had almost identical signs (both ataxic with head tremor) despite considerable total $\mathrm{PrP}^{\mathrm{sc}}$ score differences and whilst one (1451) was also teeth grinding, the other (1419) displayed signs of disequilibrium, which suggested more severe gait abnormalities.

The differences in the $\operatorname{PrP}^{\mathrm{sc}}$ profiles in $\mathrm{LL}_{141}$ sheep challenged with milk from different donors may be the results of possible strain differences although it does not explain why the same phenomenon was not observed in $\mathrm{LF}_{141}$ sheep unless the wild-type alleles $\left(\mathrm{LL}_{141}\right)$ produce greater phenotypic variability.

Similarly, the differences in the $\operatorname{PrP}^{\mathrm{sc}}$ profiles in VV and $L_{141}$ sheep challenged with brain and milk from the same goat respectively may be to some extent explained by the different survival time and clinical severity of the sheep, which may alter the proportional localisation of $\mathrm{PrP}^{\mathrm{sc}}$ immunolabelling so that sheep with longer survival times and more severe clinical signs have proportionally more intraneuronal and intraglial and less glia-associated immunolabelling, possibly as a result of progressive removal and internalization of glia-associated
$\operatorname{PrP}^{\mathrm{Sc}}$ as the disease progresses (see Fig. 4: $\mathrm{LL}_{141}$ sheep 1293 had a longer survival time and more severe clinical signs than 1294). However, this does not quite explain the profile differences seen in VV sheep where the profiles were similar in sheep with the shortest and longest survival time (see Fig. 4: VV sheep 1418 and 1425 had the shortest survival time and a similar profile to 1451 and 1452 respectively, which had the longest survival time). It also does not explain why $\mathrm{LF}_{141}$ and $\mathrm{FF}_{141}$ sheep with comparatively longer survival times than $\mathrm{LL}_{141}$ sheep accumulate most $\operatorname{PrP}^{\mathrm{sc}}$ intracellularly and lack gliaassociated $\mathrm{PrP}^{\mathrm{sc}}$, which suggests that $\mathrm{PrP}^{\mathrm{sc}}$ is more prone to be internalized in neurons and not deposited in the membrane of glial cells in sheep carrying the $F_{141}$ allele.

Discriminatory IHC using six different antibodies with different affinity to $\operatorname{PrP}^{\mathrm{sc}}$ sequences is based on the observation that truncation of the prion protein of different strains (classical scrapie, classical ovine BSE and CH1641) is dependent on tissue, cell type and location within the tissue (intra- or extracellular). Extracellular $\mathrm{PrP}^{\mathrm{sc}}$, which is not truncated, should be detected similarly with all antibodies whereas intracellular $\operatorname{PrP}^{\mathrm{Sc}}$ is truncated and therefore some antibodies (raised against the globular and $\mathrm{C}$ domains) should detect it while others (raised against the $\mathrm{N}$ terminus) may not. Whilst discriminatory IHC applied to lymphoid tissue agreed with the molecular profile obtained from lymphoid tissue, which identified the samples as consistent with classical scrapie, tests applied to CNS tissue produced a more varied result, which was dependent on PRNP polymorphisms at codon 141. This particularly affected the detection by $\mathrm{N}$-terminal antibodies, such as $12 \mathrm{~B} 2$ or $\mathrm{P} 4$. The magnitude of $\operatorname{PrP}^{\mathrm{sc}}$ immunolabelling with the $12 \mathrm{~B} 2$ antibody was reduced in sheep carrying the $F_{141}$ allele compared to $\mathrm{LL}_{141}$ sheep, which was particularly striking for extracellular and intraglial $\mathrm{PrP}^{\mathrm{sc}}$. Similarly, P4 antibody reactivity in the WB was reduced in brains from $\mathrm{LF}_{141}$ and particularly $\mathrm{FF}_{141}$ sheep. This antibody is used for the discriminatory WB to distinguish classical scrapie from BSE because brains from classical bovine BSE and experimental classical ovine BSE cases show no and greatly reduced signal, respectively [41]. $\mathrm{LL}_{141}$ sheep, including VV sheep, were classified as classical scrapie because $\operatorname{PrP}^{\text {res }}$ was detected with antibody $\mathrm{P} 4$, and the Sha31/P4 antibody ratio was as expected for classical scrapie isolates, whereas $\mathrm{LF}_{141}$ sheep produced an intermediate BSE-like profile with reduced detection with $\mathrm{P} 4$, and $\mathrm{FF}_{141}$ sheep produced a BSE-like profile with little or no $\mathrm{PrP}^{\mathrm{res}}$ detection with $\mathrm{P} 4$ and the Sha31/P4 antibody ratio was unlike classical scrapie for both genotypes.

The results obtained from the discriminatory tests suggested that proteinase $\mathrm{K}$ used for WB cleaves brain samples from sheep with the $\mathrm{L}_{141}$ allotype towards the $\mathrm{N}$ terminus from the $\mathrm{P} 4$ epitope, thus 
resulting in $\mathrm{PrP}^{\text {res }}$ detection by both Sha31 and $\mathrm{P} 4$. In contrast, proteinase $\mathrm{K}$ appeared to cleave the $\mathrm{F}_{141} \operatorname{PrP}$ protein towards the $\mathrm{C}$ terminus from the $\mathrm{P} 4$ epitope, possibly around the 141 position, thus resulting in detection by Sha31 (aa residue binding sites 148-155, see Figure 5) but not by P4 (aa 93-99). As a consequence, in $\mathrm{LF}_{141}$ sheep the $\mathrm{P} 4$ antibody only detects the $\mathrm{L}_{141}$ but not the $\mathrm{F}_{141}$ allotype resulting in decreased signal and in $\mathrm{FF}_{141}$ sheep all prion protein is of the $F_{141}$ allotype and therefore there is almost no $\mathrm{PrP}^{\mathrm{res}}$ signal with $\mathrm{P} 4$. The discriminatory IHC detected intraneuronal and intraglial $\operatorname{PrP}^{\mathrm{sc}}$ with antibodies $12 \mathrm{~B} 2$ and 521.7 in $\mathrm{LF}_{141}$ and $\mathrm{FF}_{141}$ sheep, which was unlike BSE, although the amount detected is lower by comparison with R145 and such a decrease was not seen in $L_{141}$ sheep. This suggests some cleavage of $\mathrm{F}_{141}$ allotype $\mathrm{PrP}^{\mathrm{sc}}$ by cellular enzymes but such cleavage is not as drastic as with proteinase $\mathrm{K}$ seen in the WB. The decrease in intracellular $\operatorname{PrP}^{\mathrm{sc}}$ immunolabelling with $\mathrm{N}$ terminal antibodies, which was higher in $\mathrm{LF}_{141}$ than $\mathrm{FF}_{141}$ sheep, remains unexplained unless some sort of interaction between the two allotypes makes the protein more susceptible to digestion.

The WB results highlight the difficulty in interpreting the discriminatory WB by examination of brain in cross-species transmission experiments because LF $_{141}$ and particularly $\mathrm{FF}_{141}$ sheep demonstrated a classical BSE-like profile, even though there was sufficient evidence that the isolate was not BSE: i) $L_{141}$ sheep challenged with the same isolate produced a profile consistent with classical scrapie; ii) testing of lymphoid tissue produced a molecular and pathological phenotype consistent with classical scrapie; iii) the discriminatory IHC was unlike BSE and iv) the lack of pruritus in $\mathrm{LF}_{141}$ and $\mathrm{FF}_{141}$ was inconsistent with the clinical phenotype reported for classical BSE in sheep [19]. There is currently no evidence that this poses a problem for potential misdiagnosis during discriminatory testing of positive small ruminant field cases in accordance with current European Union legislation if similar cross-species transmission occurred naturally but the process of referral for a case giving an initial BSE-like characteristic initiates further investigative testing that would rule out BSE.

\section{Conclusions}

In summary, this study provided evidence that the clinical, pathological and molecular phenotype of classical scrapie transmitted from goats to sheep is affected by PRNP polymorphisms, particularly at codon 141 , which has to be taken into account when investigating strain characteristics by laboratory methods.

\section{Additional files}

Additional file 1: study design. This file provides a graphical overview
of the design of the pilot and milk transmission studies. (PDF $197 \mathrm{~kb}$ )

Additional file 2: pruritic form of scrapie. The clip shows the clinical signs of ALRQ/ALRQ wether 1293, which was fed milk from scrapie-affected goat G1427 from $20 \mathrm{~h}$ after being born. This sheep, first shown at 1222 days of age and indicated briefly by a red circle to distinguish it from its pen mate, falls when turning. There is also excessive sinking in the hind limbs when it turns on the spot. Scratching of the back results in rising of the head and later lip licking (positive scratch test). Sixty days later, at 1282 days of age, there is evident hind limb ataxia, characterised by delayed hind foot placement and crossing of the hind limbs particularly visible when the animal turns. A positive scratch test can be elicited more easily by simply putting pressure on the spine. (MP4 $14151 \mathrm{~kb}$ )

Additional file 3: non-pruritic form of scrapie. This clip presents the clinical signs of AFRQ/AFRQ ewe 1476 at 1464 days of age following oral challenge on its day of birth with brain from scrapie-affected goat G1451. Twitching of the upper lip (repetitive myoclonus of the lip muscle) is present. There is no evidence of pruritus because this is a fully fleeced sheep without obvious wool loss and it does not respond to scratching of the back (negative scratch test). There is lack of foot placement correction when the sheep is pushed sideways suggestive of proprioceptive deficits and it briefly sits down. Hind limb ataxia is evident with excessive sinking in the hind limbs. (MP4 $13735 \mathrm{~kb}$ )

Additional file 4: clinical and pathological data. This file provides more detail about the clinical presentation, including scratch test score, and shows the individual $\mathrm{PrP}^{\mathrm{sc}}$ scores to create the brain $\mathrm{PrP}^{\mathrm{Sc}}$ profiles as well as the scores for central nervous and lymphoid tissues obtained on the discriminatory $\mathrm{HC}$. (XLSX $38 \mathrm{~kb})$

\section{Abbreviations}

$\mathrm{AA}: \mathrm{AA}_{136} \mathrm{RR}_{154} \mathrm{QQ}_{171}$; aa: amino acid; BSE: bovine spongiform encephalopathy; CNS: central nervous system; $F$ : female; $F_{141}$ : $\mathrm{AA}_{136} \mathrm{FF}_{141} \mathrm{RR}_{154} \mathrm{QQ}_{171}$; IHC: immunohistochemistry; $\mathrm{LF}_{141}: \mathrm{AA}_{136} \mathrm{LF}_{141} \mathrm{RR}_{154} \mathrm{QQ}_{171}$;

$\mathrm{LL}_{141}: \mathrm{AA}_{136} \mathrm{LL}_{141} \mathrm{RR}_{154} \mathrm{QQ}_{171} ; \mathrm{M} / \mathrm{N}$ : male neutered; PRNP: prion protein gene; PrPres $^{\text {r }}$ proteinase-resistant form of $\operatorname{PrP}^{\text {sc. }}$; $\operatorname{PrP}^{\text {sc }}$ : scrapie-associated prion protein; RAMALT: recto-anal mucosa-associated lymphoid tissue; SD: standard deviation; TSE: transmissible spongiform encephalopathy; UK: United Kingdom; $\mathrm{W}: \mathrm{W}_{136} \mathrm{RR}_{154} \mathrm{QQ}_{171} ; \mathrm{WB}$ : Western immunoblot

\section{Acknowledgements}

We are grateful to many present and former members of staff in the Animal Sciences Unit and the Pathology Department, APHA Weybridge, for their contribution to and support of this project. We also thank Dr. M Simmons (APHA Weybridge) for critical review of this manuscript.

\section{Funding}

Milk collection, production of scrapie-free lambs and the transmission studies were funded by the UK Department for Environment, Food and Rural Affairs (projects SE1956, SE1931 and SE1855), which had no influence over the design of the study, collection, analysis, and interpretation of data and writing the manuscript.

\section{Availability of data and materials}

The data supporting the conclusions of this article are included in the manuscript and as additional file. Data on the goats that provided the inocula and milk can be found in previously published manuscripts [10, 12] in the main text or as additional file.

\section{Authors' contribution}

TK managed the study, performed the clinical examinations, supported by LJP, interpreted the clinical data and wrote the manuscript. BRD and MJC were responsible for the Western immunoblot examination and its interpretation. SC was responsible for the genotyping data. LG carried out the detailed pathological examinations, analysed and interpreted the pathological data. All authors read, contributed to and approved the final manuscript. 


\section{Competing interests}

The authors declare that they have no competing interests.

\section{Consent for publication}

Not applicable.

\section{Ethics approval}

All procedures involving animals were approved by the United Kingdom (UK) Home Office under the Animals (Scientific Procedures) Act 1986 under project licence 70/7745 and approved by the institutional ethical committee at the Animal and Plant Health Agency Weybridge. Housing and care of animals was in accordance with the Home Office code of practice.

\section{Publisher's Note}

Springer Nature remains neutral with regard to jurisdictional claims in published maps and institutional affiliations.

\section{Author details}

${ }^{1}$ Animal Sciences Unit, Animal and Plant Health Agency Weybridge, Addlestone, UK. ${ }^{2}$ Pathology Department, Animal and Plant Health Agency Weybridge, Addlestone, UK. ${ }^{3}$ Central Sequencing Unit, Animal and Plant Health Agency Weybridge, Addlestone, UK. ${ }^{4}$ Pathology Department, Animal and Plant Health Agency Lasswade, Penicuik, UK.

\section{Received: 17 November 2016 Accepted: 21 April 2017}

\section{Published online: 04 May 2017}

\section{References}

1. Brotherston JG, Renwick CC, Stamp JT, Zlotnik I, Pattison IH. Spread and scrapie by contact to goats and sheep. J Comp Pathol. 1968;78(1):9-17.

2. Hadlow WJ, Kennedy RC, Race RE, Eklund CM. Virologic and neurohistologic findings in dairy goats affected with natural scrapie. Vet Pathol. 1980;17(2):187-99.

3. Pattison $\mathrm{H}$. The relative susceptibility of sheep, goats and mice to two types of the goat scrapie agent. Res Vet Sci. 1966;7(2):207-12.

4. Hunter N, Bossers A. The PrP genotype as a marker for scrapie susceptibility in sheep. In: Hörnlimann B, Riesner D, Kretzschmar H, editors. Prions in humans and animals. Berlin: de Gruyter; 2006. p. 640-7.

5. Moum T, Olsaker I, Hopp P, Moldal T, Valheim M, Moum T, Benestad SL. Polymorphisms at codons 141 and 154 in the ovine prion protein gene are associated with scrapie Nor98 cases. J Gen Virol. 2005;86(1):231-5.

6. González L, Jeffrey M, Dagleish MP, Goldmann W, Sisó S, Eaton SL, Martin S, Finlayson J, Stewart P, Steele P, Pang Y, Hamilton S, Reid HW, Chianini F. Susceptibility to scrapie and disease phenotype in sheep: cross-PRNP genotype experimental transmissions with natural sources. Vet Res. 2012:43:55.

7. Vaccari G, Panagiotidis CH, Acin C, Peletto S, Barillet F, Acutis P, Bossers A, Langeveld J, Van Keulen L, Sklaviadis T, Badiola JJ, Andréoletti O, Groschup MH, Agrimi U, Foster J, Goldmann W. State-of-the-art review of goat TSE in the European Union, with special emphasis on PRNP genetics and epidemiology. Vet Res. 2009;40(5):48.

8. Schneider DA, Madsen-Bouterse SA, Zhuang D, Truscott TC, Dassanayake RP, O'Rourke Kl. The placenta shed from goats with classical scrapie is infectious to goat kids and lambs. J Gen Virol. 2015;96(8):2464-9.

9. Konold T, Thorne L, Simmons HA, Hawkins SAC, Simmons MM, González L. Evidence of scrapie transmission to sheep via goat milk. BMC Vet Res. 2016;12(1):1-10

10. González L, Martin S, Sisó S, Konold T, Ortiz-Peláez A, Phelan L, Goldmann W, Stewart P, Saunders G, Windl O, Jeffrey M, Hawkins SAC, Dawson M, Hope J. High prevalence of scrapie in a dairy goat herd: tissue distribution of diseaseassociated PrP and effect of PRNP genotype and age. Vet Res. 2009:40:65.

11. Wells GAH, SAC H. Animal models of transmissible spongiform encephalopathies: experimental infection, observation and tissue collection. In: Lehmann S, Grassi J, editors. Techniques in prion research. 1st ed. Basel: Birkhäuser Verlag; 2004. p. 37-71.

12. González L, Martin S, Hawkins SA, Goldmann W, Jeffrey M, Sisó S. Pathogenesis of natural goat scrapie: modulation by host PRNP genotype and effect of co-existent conditions. Vet Res. 2010:41(4):48.

13. Konold T, Bone GE, Phelan LJ, Simmons MM, González L, Sisó S, Goldmann W, Cawthraw S, Hawkins SAC. Monitoring of clinical signs in goats with transmissible spongiform encephalopathies. BMC Vet Res. 2010;6:13.
14. Simmons HA, Simmons MM, Spencer Yl, Chaplin MJ, Povey G, Davis A, OrtizPelaez A, Hunter N, Matthews D, Wrathall AE. Atypical scrapie in sheep from a UK research flock which is free from classical scrapie. BMC Vet Res. 2009;5:8.

15. Saunders GC, Cawthraw S, Mountjoy SJ, Hope J, Windl O. PrP genotypes of atypical scrapie cases in great Britain. J Gen Virol. 2006;87(11):3141-9.

16. Konold T, Moore SJ, Bellworthy SJ, Terry LA, Thorne L, Ramsay A, Salguero FJ, Simmons MM, Simmons HA. Evidence of effective scrapie transmission via colostrum and milk in sheep. BMC Vet Res. 2013;9(1):99.

17. Konold T, Phelan L. Clinical examination protocol to detect atypical and classical scrapie in sheep. J Vis Exp. 2014;83:-e51101.

18. Konold T, Bone GE. Heart rate variability analysis in sheep affected by transmissible spongiform encephalopathies. BMC Res Notes. 2011;4(1):539.

19. Konold T, Bone G, Vidal-Diez A, Tortosa R, Davis A, Dexter G, Hill P, Jeffrey M, Simmons MM, Chaplin MJ, Bellworthy SJ, Berthelin-Baker C. Pruritus is a common feature in sheep infected with the BSE agent BMC Vet Res. 2008;4:16

20. Jeffrey M, González L, Chong A, Foster J, Goldmann W, Hunter N, Martin S. Ovine infection with the agents of scrapie ( $\mathrm{CH} 1641$ isolate) and bovine spongiform encephalopathy: immunochemical similarities can be resolved by immunohistochemistry. J Comp Pathol. 2006;134(1):17-29.

21. Martin S, González L, Chong A, Houston FE, Hunter N, Jeffrey M. Immunohistochemical characteristics of disease-associated PrP are not altered by host genotype or route of inoculation following infection of sheep with bovine spongiform encephalopathy. J Gen Virol. 2005;86:839-48.

22. TSE strain characterisation in small ruminants. A technical handbook for national reference laboratories in the EU [https://science.vla.gov.uk/tse-labnet/documents/tse-oie-rl-handbook.pdf].

23. Petrie L, Heath B, Harold D. Scrapie: report of an outbreak and brief review. Can Vet J. 1989;30(4):321-7.

24. Scott PR, Henshaw CJ. Increasing the accuracy of the provisional antemortem diagnosis of scrapie. Agri Pract. 1995;16(3):21-5.

25. Tyler JW, Weaver DM, Turk JR, O'Rourke Kl, Harrington MG, Taylor W, Jenny A. Naturally occurring scrapie in Southdown sheep. J Vet Intern Med. 1999; 13(3):213-6.

26. Parry HP. Scrapie and related myopathies in sheep. Vet Rec. 1957;69(3):43-55

27. Lowrie M, Garosi L. Classification of involuntary movements in dogs: tremors and twitches. Vet J. 2016;214:109-16.

28. García de Jalón JA, De las Heras M, Balaguer L, Badiola JJ. Enfermedad del prurigo lumbar (scrapie) en la oveja: diagnóstico en 5 rebaños. Med Vet. 1987:4(5-6):303-10.

29. Healy AM, Weavers E, McElroy M, Gomez-Parada M, Collins JD, O'Doherty E, Sweeney T, Doherty ML. The clinical neurology of scrapie in Irish sheep. J Vet Intern Med. 2003;17(6):908-16.

30. Konold T, Bone G, Ryder S, Hawkins SAC, Courtin F, Berthelin-Baker C. Clinical findings in 78 suspected cases of bovine spongiform encephalopathy in great Britain. Vet Rec. 2004;155(21):659-66.

31. Konold T, Sayers AR, Sach A, Bone G, van Winden S, Wells G, Simmons M, Stack M, Wear A, Hawkins S. Relationship between clinical signs and postmortem test status in cattle experimentally infected with the bovine spongiform encephalopathy agent. BMC Vet Res. 2010;6(1):53

32. Maltête D, Guyant-Maréchal L, Mihout B, Hannequin D. Movement disorders and Creutzfeldt-Jakob disease: a review. Parkinsonism Relat Disord. 2006:12(2):65-71.

33. Ulvund MJ. Clinical findings in scrapie. In: Hörnlimann B, Riesner D, Kretzschmar $\mathrm{H}$, editors. Prions in humans and animals. Berlin: de Gruyter; 2006. p. 398-407.

34. Konold T, Bone G, Ortiz-Pelaez A, Tortosa R, Clifford D, Dexter G, Simmons MM, Spiropoulos J, Berthelin-Baker CF. Associations of clinical signs and prion protein genotypes in British sheep with scrapie. Dtsch Tierärztl Wochenschr. 2009:116(11):380-8

35. Spiropoulos J, Casalone C, Caramelli M, Simmons MM. Immunohistochemistry for PrPSc in natural scrapie reveals patterns which are associated with the PrP genotype. Neuropathol Appl Neurobiol. 2007; 33(4):398-409.

36. Madec JY, Groschup MH, Calavas D, Junghans F, Baron T. Protease-resistant prion protein in brain and lymphoid organs of sheep within a naturally scrapie-infected flock. Microb Pathog. 2000;28(6):353-62.

37. González L, Martin S, Begara-McGorum I, Hunter N, Houston F, Simmons M, Jeffrey M. Effects of agent strain and host genotype on PrP accumulation in the brain of sheep naturally and experimentally affected with scrapie. J Comp Pathol. 2002;126(1):17-29. 
38. Madec JY, Simon S, Lezmi S, Bencsik A, Grassi J, Baron T. Abnormal prion protein in genetically resistant sheep from a scrapie- infected flock. J Gen Virol. 2004;85:3483-6.

39. Ersdal C, Ulvund MJ, Espenes A, Benestad SL, Sarradin P, Landsverk T. Mapping PrPSc propagation in experimental and natural scrapie in sheep with different PrP genotypes. Vet Pathol. 2005;42(3):258-74.

40. Vargas F, Lujan L, Bolea R, Monleon E, Martin-Burriel I, Fernandez A, De Blas I, Badiola JJ. Detection and clinical evolution of scrapie in sheep by $3 \mathrm{rd}$ eyelid biopsy. J Vet Intern Med. 2006;20(1):187-93.

41. Stack M, Jeffrey M, Gubbins S, Grimmer S, González L, Martin S, Chaplin M, Webb P, Simmons M, Spencer Y, Bellerby P, Hope J, Wilesmith J, Matthews D. Monitoring for bovine spongiform encephalopathy in sheep in great Britain, 1998-2004. J Gen Virol. 2006;87(7):2099-107.

Submit your next manuscript to BioMed Central and we will help you at every step:

- We accept pre-submission inquiries

- Our selector tool helps you to find the most relevant journal

- We provide round the clock customer support

- Convenient online submission

- Thorough peer review

- Inclusion in PubMed and all major indexing services

- Maximum visibility for your research

Submit your manuscript at www.biomedcentral.com/submit
Biomed Central 